\title{
The role of social responsibility in protecting the environment - a case of the petrochemical companies in Alexandria Governorate
}

\author{
Rasha Kamal El-Deen El-Mallah \\ Financial and Administrative Affairs,
} General Authority For Literacy and Adult Education, Alexandria, Egypt

Alia Abd el Hamid Aref

Public Administration, FEPS, Cairo, Egypt and Public Administration, Faculty of Economics and Political Science, Cairo University, Giza, Egypt, and

\author{
Sherifa Sherif \\ Faculty of Economics and Political Science, Cairo University, Giza, Egypt
}

\begin{abstract}
Purpose - The purpose of this paper is as follows: First, understanding the nature of the relationship between corporate adoption of the concept of societal responsibility [availability of environmental awareness, clear vision of the impact of societal responsibility on financial performance, managers informing employees of the latest developments in societal responsibility programs, managers' response to their corporate social responsibility (CSR) proposals] in the form of an annual report that supports the success of the company's objectives, the company's management encourages employees to participate collectively in societal responsibility programs and to protect the environment from pollution in the petrochemical industry. Second, understand the nature of the relationship between the dimensions of corporate social responsibility concept (cultural, social, economic, ethical and legal) and protect the environment from pollution in the petrochemical industry. Third, the research also seeks to show the role of societal responsibility and its application in the petrochemical companies to protect the environment from pollution in The Governorate of Alexandria Egypt, and come out with results and recommendations that could help protect the environment from the forms of environmental pollution resulting from the production processes of this industry.

Design/methodology/approach - The researcher has relied on each of the following approaches: Case study methodology is a research strategy aimed at solving a problem or facing a particular situation. It is based on preliminary hypotheses through full analysis of all data collected and recorded. Which depends on the study of a limited number of cases or vocabulary in-depth comprehensive study through the study of all or a large number of variables overlapping and interrelated and influential on the problem under consideration. Thus, it provides a deep and rich understanding of what is going on around the research and the processes that are related to it, and not only the external or apparent description of the situation or phenomenon; it cares about the total description and looks at the particles, in relation to the whole. Quantitative approach: by giving

(C) Rasha Kamal El-Deen El-Mallah, Alia Abd el Hamid Aref and Sherifa Sherif. Published in Review of Economics and Political Science. Published by Emerald Publishing Limited. This article is published under the Creative Commons Attribution (CC BY 4.0) licence. Anyone may reproduce, distribute, translate and create derivative works of this article (for both commercial and noncommercial purposes), subject to full attribution to the original publication and authors. The full terms of this licence may be seen at http://creativecommons.org/licences/by/4.0/legalcode
\end{abstract}

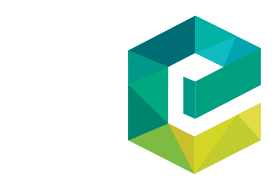

Review of Economics and Political Science 
a numerical description indicating the size or size of the phenomenon or the degree of association with the phenomenon. Other phenomena. Accordingly, the role of the petrochemical companies in Alexandria Governorate, and the social responsibility programs carried out within the governorate in terms of importance, growth and requirements, and the most important characteristics and constraints and components and methods of work and developments have been described. Thus, the researcher can analyze the relationship between CSR and environmental protection from pollution in Alexandria Governorate.

Findings - There is paucity in the studies that dealt with the relationship between CSR and environmental protection against pollution in public organizations. There is agreement among the sample on the importance and feasibility of adopting the concept of social responsibility and placing it at the top of the top management concerns, especially in the field of petrochemical companies. With the need to take concrete implementation measures to support social responsibility programs aimed at serving the community among all stakeholders. The effective implementation of the mechanisms for the implementation of meaningful social responsibility programs requires fundamental changes in management practices, existing organizational structures and the quality of personnel working in the relevant departments, in general, and the social responsibility group, in particular, which may be difficult for political and economic reasons.

Research limitations/implications - Time: The study period was set from 2015 to 2017. Place: The study focuses on the petrochemical companies operating in Alexandria. Humanity: The study focuses on the employees of the petrochemical companies operating in Alexandria Governorate.

Practical implications - The adoption of social responsibility positively affects the protection of the environment from pollution, and this effect shows that the adoption of the concept of corporate social responsibility is influenced by the following factors: increasing the participation of workers with healthy environmental contributions to the productive process; increasing the companies' economic and social activities toward protecting the environment from pollution; increasing the capacity of companies to pay greater costs to preserve the environment; increasing the awareness of green consumers with the products it offers Companies; development of continuous internal work environment companies; and clearly defined strategy followed in social responsibility programs.

Social implications - The social responsibility of the public organizations derives their strength through, first, the keenness of these organizations to analyze the variables of the ethical dimension of social responsibility and their availability, which will lead the organizations to provide their services with the highest quality and sincerity. That this analysis (ethics of individuals) as training members of the social responsibility team to solve problems using brainstorming and provide employees with official data related to improving work (ethics of leadership), such as the identification of business objectives through the participation of managers with subordinates, and the punishment of workers who exhibit immoral behaviors (ethics of productive processes) as a decision-making process to ethical standards regardless of the costs involved. When there is an immoral behavior and managers are responsible for implementing the changes needed to reach the targeted outcomes), second, promote partnerships with other relevant sectors for community service.

Originality/value - According to the results of the previous studies and the applied study results, the researcher would like to submit a mechanism to the directors and heads of the boards of directors of the Egyptian petrochemical companies under study.

Keywords Egypt, Corporate social responsibility, Environment protection, Petrochemical industry, Alexandria

Paper type Research paper

\section{Introduction}

The evaluation of industrial companies is no longer measured by the extent to which the company achieves financial profits or a larger quantity of goods and services. A number of modern concepts have emerged in which organizations have become a legal entity that is treated as a citizen with direct social effects on the surrounding society, especially on the environmental field in which it operates.

The most important of these concepts is the concept of corporate social responsibility (CSR) towards the society in which it is located, the safety and health of its products, and 
contribution to a range of social activities from combating poverty and pollution control, and the pivotal role it plays in sustainable development processes in its continuous commitment to providing services and goods that achieve a better standard of living and contribute to the development of the environment to benefit them at the community level, and attention to societal responsibility towards the external environment and internal of those organizations.

Nowadays, the importance of applying the concept of societal responsibility in Egyptian public sector has become a new matter of interest for researchers and practicing administrators. How can societal responsibility be an integral part of a company's strategy to interact with society?; Which are supposed to undertake the tasks of making and implementing public policies in general and implementing of environmental policies in particular?; Where the planning of these companies did not include consideration of the environmental and community aspects and increase development, especially in the poor and marginalized areas and increase the green areas and reduce the rates of desertification and reduce the emission of carbon dioxide which is caused of the activities of factories, and increasing afforestation rates and reduce unemployment rates, awareness of fresh water purification and wastewater treatment, treatment of harmful waste and finding safe places for disposal; maintain non-renewable resources, reduce the rates of corruption and bribery and increase levels of transparency, accountability and accountability.

Just as there is a large group of organizations with a high commitment to the environment and the surrounding society, there are, on the other hand, organizations that are not committed and have no initiative in seeking to protect the environment from pollution as a result of the environmental effects of polluting the environment. The environment provides the food consumed by the community and provides it with the air and clean water it needs, and the raw materials that these organizations receive from the environment are brought back to them in the form of waste of various shapes and species, which leads to the rapid work to protect the human and the environment from pollution.

The petrochemical industry is one of the most important strategic industries in Egypt. However, these companies are a source of environmental pollution, which was monitored according to the reports of the Ministry of Environment in some industrial areas of Alexandria, Egypt.

The industrial companies in general and the petrochemical companies in particular are not charitable companies, but their first concern is to achieve a financial return commensurate with the size of their investment. Therefore, these industrial companies adopt their societal responsibilities in general and the environment in particular, which entails additional costs that may not result from other competitors, these companies in solving their environmental problems are working to add competitive advantage to others, as well as supporting the reputation of their products in the internal and external markets. It also helps to accomplish its tasks with different parties with its environmental commitment and obtaining various certificates in this field, the environmental public ecology of the government supports the trend to protect the environment from pollution.

Undoubtedly, urging organizations to adopt societal responsibility leads them to fulfill their commitments to the environment and to support their environmental management within their capabilities and responsibilities as this commitment is an integral part of social commitment.

\section{Literature review}

The petrochemical industry is based upon the production of chemicals from petroleum and also deals with chemicals manufactured from the byproducts of petroleum refinery. At the 
preliminary stages of chemical plant development and design, the choice of chemical process route is the key design decision. In the past, economics were the most important criterion in choosing the chemical process route. Modified studies imply that the two of the important planning objectives for a petrochemical industry, environmental risk and the industrial safety involved in the development. So the environmental issues especially CSR and environmental protection from pollution has now become important considerations due to the potential harmful impacts produced by petrochemical industry.

\subsection{Theoretical background of corporate social responsibility}

Frynas and Yamahaki (2016, pp. 265-270), summarized the theories used to account for the CSR phenomenon. In a nutshell, the stakeholder theory (Freeman, 1984) was most frequently used in CSR studies, followed by institutional theory (Scott, 2001) and legitimacy theory (Suchman, 1995, p. 578). Moreover, the authors classified the theories with respect to CSR practices into the external- and internal-driver groups. The stakeholder theory, institutional theory, legitimacy theory and resource independence theory (Pfeffer and Salancik, 1978) belong to the external-driver group, while the internal-driver group includes the Edith Penrose's resource-based view (Lockett and Thompson, 2004, p. 199; Rugman and Verbeke, 2002, p. 777) and (Jensen and Meckling, 1976, p. 325) agency theory.

According to the resource-based view, firms exploit internal resources (e.g. specialized skills) to create competitive advantages. Under the agency theory, management engages in CSR to communicate to stakeholders about firms' transparency (Frynas and Yamahaki, 2016, p. 260). However, there are replications between different external and internal-driver theories; therefore, the collective use of theories, rather than individually, would offer a more comprehensive view of the CSR phenomenon (Frynas and Yamahaki, 2016, p. 281; Reverte, 2009, p. 358).

As this research aims to determine the role of societal responsibility and its application in the petrochemical companies to protect the environment from pollution in The Governorate of Alexandria - Egypt.

Companies should work to balance their participation in CSR programs, as very limited participation can have an impact on the company's reputation, and the very broad participation of the company may incur financial losses. It must focus on "social responsibility programs" Ideal for businesses. Regardless of the size of the company is small, medium or large, it must describe its strategy of social responsibility with clearly defined objectives, key performance indicators are measurable and disclosure of frameworks in place.

\subsection{Corporate social responsibility in Egypt}

Although research studies have become more attentive to examining CSR in developing countries, studies from African countries are still limited (Kolk and Lenfant, 2010, p. 247). With the exception of South Africa, Nigeria and Lebanon (Jamali et al., 2017, p. 18).

According to the World Bank projections, Egypt's economic growth was expected to improve significantly reaching 4 per cent in 2017. This indicates that the Egyptian economy experienced a rapid recovery and maintained its stability in spite of unfavorable political and social conditions. In this respect, the Arab Spring had major consequences for firm operations but did not result in a breakdown of the economy (Letmathe and El-Bassiouny, 2019, p. 6).

Marquis and Raynard (2015, pp. 297-299) highlighted corporate institutional strategies that are mainly applied in weak and challenging institutional environments. The authors classified them into three main strategies, namely, relational, infrastructure-building and 
socio-cultural bridging. Organizations undertaking relational strategies manage their relationships with both internal and external stakeholder groups and the government to increase the stability and certainty of their resources and to improve their competitive place in the market. Infrastructure building strategies, on the other hand, focus on building absent or limited regulatory and physical infrastructure to facilitate business activities. Organizations adopting sociocultural- bridging strategies focus on improving their sociocultural and demographic environment, including poverty and political and social unrest, to enhance economic development and trade. All of these strategies aim at effectively managing challenging institutional environments to enhance the firms' performance and to ensure their long-term survival.

The findings of Letmathe and El-Bassiouny (2019, p. 12) that some companies added a "CSR" section to their 2012 annual reports. However, there is no substantial change in the disclosure of CSR-related content in the 2012 annual reports compared to Years ago. The political context in which these findings are assessed needs to be taken into account. The national and the institutional environments in which the firm operates affect the promotion of the CSR practice. Egyptian companies suffered financial deficiencies (at least during the revolution year) that would normally redirect their efforts to "survival" economic factors, such as productivity and profitability, rather than to "luxurious" CSR initiatives. However, in spite of these restrictions, sample companies continued their involvement in CSR practices.

There is no doubt that the Egyptian companies contribute annually to a large amount of donations in various charitable aspects. It has contributed to the construction of mosques, the establishment of schools and hospitals, and the support of orphanages, the handicapped and many aspects of righteousness.

However, these donations are spontaneous and ill-considered, which neglects national priorities and focuses on specific areas. As most companies are located within Cairo and Alexandria, this makes them serve certain specific groups without the other. These donations also go to individuals, which makes them go to spend my life and do not go to establish large institutions and facilities, or long-term projects.

Therefore, a central mechanism must be developed that sets out a plan to redistribute corporate contributions according to national and social priorities to achieve real sustainable development.

\subsection{The literature review of the relationship between societal responsibility and environmental protection}

To develop sustainable business through the implementation of corporate social responsibility, the following are essential: informing and sensitizing all stakeholders, opening channels of communication and transparency between companies and stakeholders, cooperation, strengthening the legal and institutional framework, and voluntary commitment to look at the environment in the long run by companies (Stojanović et al., 2016, p. 11).

Protecting the environment is essential for companies to take care of environmental issues through the management of societal responsibility programs that promote environmental protection, as well as the need for investors and investors to invest in green, and to formulate their investment strategies to take into consideration the environmental aspects (Andrei et al., 2014, p. 5).

The leaders of companies are responsible for the impact of their companies on society and the natural environment beyond the legal commitment and responsibility of individuals and more experienced leaders can gain new perspectives on how to grow in their approach 
to sustainability and how to develop innovative business models, A pioneer in the principle of senior management and entrepreneurs (Bhagwat, 2011, p. 8).

The Polish public sector institutions are taking their first steps in developing internal environmental responsibility because there are no internal mechanisms for environmental responsibility and that there is a significant difference between the environmental responsibility of the organizations in Poland and their counterparts abroad (Hawrysz and Foltys, 2015, p. 5).

The laws of environmental protection in India in 1986, in addition to a variety of the environmental policy laws of 2006 are not complied with by companies, which led to the condemnation of industries that damaged the environment and resulted in environmental imbalances. The CSR agenda is only formal as they announce societal responsibility programs to prove that they Officials Socially and human society as a whole to save face, but the fact is that they do this to hide the real activities that they do and do not care about the issues and environmental damage that result (Tiwari, 2010, p. 4).

Companies should adopt the concept of social responsibility for their impact on the environment, consumers, employees, communities, stakeholders and all members of society. Accordingly, these companies are working to promote the public interest by encouraging the growth and development of society, and eliminating practices harmful to society.

It must also set limits and controls for growth and progress to be the basis for the wellbeing, prosperity and happiness of the community to live in a clean, pollution-free environment, and not to waste their time in exploiting natural resources and neglecting the right of future generations to benefit as much as they enjoyed.

\subsection{The literature review on societal responsibility}

The results of some studies show a positive association between financial performance and CSR (Platonova et al., 2018, p. 461), corporate social responsibility (CSR) practices and models are mainly Western-driven (Jammulamadaka, 2018, p. 12).

And the enabling environment is a product of a strong institutional environment that is commonly found in developed markets. On the other hand, lack of competition among firms, inefficient enforcement of regulations and marginal roles of NGOs and employee unions are likely to cause institutional voids that create challenging CSR environments (Amaeshi et al., 2016, p. 137).

The findings of Amaeshi et al. (2016, p. 149) suggest that in weak institutional environments, companies adopt "CSR adaptive mechanisms" that act as an "institutional buffer," which immunes companies from their surrounding non-enabling institutional environment and enable them to successfully implement CSR practices.

The impact of the dimensions (responsibility for handling customer complaints, responsibility for providing security to customers when using the service, responsibility for providing adequate and adequate information about the service) on customer satisfaction is greater than the impact of dimensions (responsibility for maintaining customer health, Showing products in suitable places for customers), which illustrates the need to prioritize corporate social responsibility concerns (Abu-Halaqan, 2014, p. 133).

The most important findings of Arafa (2015) study are:

- an impact on the ethical responsibility of the organization to empower its employees;

- the commitment of organizations to assume ethical responsibility for the environment in which they operate; and 
- there are some fears of departmental directors of delegation of powers and responsibilities.

Ethical codes and moral training do not affect the performance of local government employees, and that the most important element of behavior promotion is ethical leadership, the most important factor in encouraging employees to be ethical. The study noted that the lack of ethical leadership will lead to fraud waste, corruption, ill-treatment and the collapse of the organization (Elmore, 2011, p. 163).

There is an inverse relationship between financial performance and CSR over the years of study, which may be due to the recent application of CSR practices by Egyptian companies. Consequently, the positive impact of these practices has not yet been reflected in financial performance in a stable general climate for most periods studying (Mustafa, 2013, p. 120).

The study of Al-Tira (2012) concluded that societal responsibility should be integrated into the message, vision and philosophy of Libyan companies and their culture, as well as the need for Libyan industrial companies to fully disclose information related to the social activities carried out during the year and the social costs resulting from them.

One of the pillars of the companies' start up is the complete conviction of shareholders, owners, board of directors and executive management of the importance and importance of social contribution and community service based on a sense of social responsibility and the principle of social solidarity, and any start of companies that are simple and simple are donations and donations to committees and charities accredited and participate in events and events social issues.

Therefore, there is an institutional shift in the establishment of specialized departments in the management and supervision of areas of social responsibility in an institutional and professional manner, which is administratively linked to the executive heads of companies and the allocation of independent financial budgets.

\subsection{The literature review on environmental protection}

In India TNCs are more effective in paying taxes than local companies, and that foreign affiliates with knowledge of CSR implementation are paying taxes at a higher rate than those of foreign companies less familiar with the concept. This set of findings suggests that TNCs operating in India believe that paying taxes in developing countries has to do with the implementation of CSR (Muller and Kolk, 2012, p. 22).

The study of Zanat (2016) concluded that:

- The activity of the economic institutions in Algeria has negative effects on the environment. A large group of these institutions do not pay much attention to integrating the environmental dimension into their activities.

- The economic institutions in Algeria are trying to show their interest in the environment by participating in scientific conferences related to the preservation of the environment and protection from pollution. Environmental awareness has been established in these institutions by attempting to contribute to reducing the environmental pollution.

- Environmental taxes and fees are an instrument by which the state intervenes to guide the environmental behavior of economic institutions, but they remain very weak, due to their low rates, poor productivity, and inefficient methods of collection.

- Pressures of parties with an active interest in the environmental field, these institutions to absorb this pressure through some environmental initiatives, which are few in view of the environmental damage caused by the economic institution. 
The results of Sajib et al. (2011) study were as follows:

- There are significant effects of different components of environmental management at the level of current output.

- The most important ingredient for the compost industry is the environmental component.

- The full implementation of ISO 14001 certification in the fertilizer industry in Bangladesh contributes to sustainable development.

Environmental law in Egypt is based on the importance of linking sustainable development and the environment with all its elements and contents. The Environmental Law has been concerned with the studies of environmental impact assessment, which is the new line of defense for environmental protection in the future. No project or facility will be allowed to start its activities without the EIA studies for this project. The law was also called for the establishment of an environmental protection fund to support the project, studies of environmental protection, the establishment of environmental monitoring networks covering the Egyptian territory and recording all pollution and declare emergency at risk.

\section{Conceptual framework}

Before analyzing the relationship between corporate social responsibility and protect the environment from pollution, we first should define them separately.

\subsection{Corporate social responsibility}

3.1.1 Define corporate social responsibilty according to professional organizations. According to the increasing importance of societal responsibility as concept, many professional organizations many professional organizations have tried to provide a specific definition of CSR. These definitions are:

Definition of the Organization of International Standards (ISO): Societal responsibility can be defined as "the responsibility of the organization for the effects of its decisions and activities on society and the environment, represented by transparency and ethical behavior consistent with sustainable development and the welfare of society, as well as taking the expectations of shareholders". As (ISO 26000): Societal responsibility is defined as "translating the decisions and activities of the organization towards society and the environment by adopting transparent and ethical behavior that contributes to sustainable development (including health and welfare in society) takes into account the expectations of stakeholders, And conforms to international standards, so that this concept is incorporated into the organization as a whole, and is practiced and applied at different administrative levels". (The Boston College Center for Corporate Citizenship - BCCCC) defines Corporate social responsibility as "the business strategy that defines the value model on which the company is based in carrying out its tasks and choices by executives, managers, and employees for engagement in the community".

3.1.2 Definition of societal responsibility according to academic studies. Academic studies sought to define CSR as follows:

In terms of modern management, the origin of the societal responsibility concept goes back to the 1950s (Carroll, 1999, p. 70). As (Carroll, 1999, p. 70): CSR is "The business commitments of policy-making, decision-making and the pursuit of a set of desired behaviors in the light of the goals and values of society" (Othman, 1999, p. 9) defines the responsibility of the establishment for the negative environmental effects resulting from its activity in response to social pressure forces, which necessitate carrying out certain 
mandatory activities to satisfy the social requirements imposed by the prevailing laws, policies and social norms".

Finally, as (Cameron, 2009, p. 1):

the need for the Organization to examine its decisions and actions so as to take into account the interests of the relevant parties - the parties of workers, customers, the community and the environment - as well as the pursuit of profits.

And as (Berger-Walliser and Scott, 2018, p. 177):

Corporate social responsibility, as undertaken by a corporation or directed by a state, includes activities that internalize costs for externalities resulting directly or indirectly from corporate actions, or processes and actions to consider and address the impact of corporate actions on affected stakeholders, which are undertaken at least in part because of a recognized moral or ethical duty to society and stakeholders beyond the corporation's owner/shareholders.

3.1.3 Setting the corporate social responsibility definition for this study. The current study concludes that CSR is defined as a culture of commitment to the responsibility of companies towards society, so that the interests of all parties to the activity become part of their strategic plans, while providing support from senior management towards sustainable development, including Ensuring the development, prosperity and well-being of society as a whole, protecting and reducing pollution from the environment, developing programs for the training and development of corporate personnel, improving the quality of products and services provided and complying with the laws, regulations and policies of the state.

\subsection{Environment protection}

In recent decades, many environmental problems have increased as the result of human activities and unplanned management of the technological development those interference eco-systems.

Environmental protection is a social movement. The protection of environment has assumed even more importance in recent times with increased industrialization resulting not only in overdraw of natural resources but also pollution of air, water, flora and fauna. While development is essential to every economy, it is also essential that no irreparable damage be caused to the eco-system (The Institute of Company Secretaries of India (ICSI), 2005, p. 301).

Environmental pollution is defined as:

$[\ldots]$ the change in the natural characteristics of the elements controlling the environment in which effect human beings live -air, water and soil- change that is detrimental to the improper use of these elements by adding substances that are alien to them. The contamination may be biologically, chemically, Waste and harmful waste or lack of hygiene (Al-Maazawy, 2004, p. 8).

Environmental pollution can define as:

Any change in the characteristics of the environment that directly or indirectly affects human health and influences the exercise of its natural life, or damage to natural factors, organisms or biological diversity.

And it also defined as "quantitative change" And qualitative in the environmental components leads to imbalance in nature" Christopher J. (Barrow, 2000, p. 25). Or "an undesirable change in the characteristics of the chemical, physical and biological component of environment" (Wagner, 1994, p. 20). And it can be "any quantitative or qualitative change in the components of the living or non-living environment that ecosystems cannot absorb without losing their equilibrium” (Dabis, 1997, p. 15). 

pollution is defined as:

[...] any change in environmental properties that leads directly or indirectly to undermining man's health, negatively impacting his ability to lead a normal life, or harming natural habitats, living organisms or biological diversity

And environmental degradation can define as "effect on the environment that reduces its value, or changes its nature, depletes its resources or harms living organisms or monuments". While environmental protection is defined as:

[...] protecting and promoting the components of the environment and preventing or reducing their degradation or pollution, these components encompass air, seas, internal waters, including the river Nile, lakes and subterranean water, land, natural protectorates, and other natural resources.

Environmental protection can be defined as the prevention of unwanted changes to ecosystems and their constituent parts. This includes the protection of ecosystems and their constituent parts from changes associated with human activities; and the prevention of unwanted natural changes to ecosystems and their constituent parts. Environmental remediation is distinct from environmental protection as its primary objective is to restore an ecosystem or natural environment to a previous state; that is, like exploitation, it is associated with deliberately induced change, as opposed to the prevention of change (Hamilton and Bastianoni, 2019, p. 320). And it is policies and procedures aimed at conserving the natural resources, preserving the current state of natural environment and, where possible, reversing its degradation (Zhang et al., 2019, p. 1027).

It is necessary to gain a good understanding of the socio-economic aspects of environmental protection to ensure that measures taken to protect the environment do not place undue burdens on enterprise and society (Environmental Protection Agency, 2013, p. 11).

\subsection{Setting the environmental protection definition for this study}

However, the vision of the current study is that environmental pollution can be defined as all that affects total elements of the living environment of plants, animals, humans and non-living organisms like air, soil and water, whether affects directly or indirectly. This means that any change in the natural qualities of the elements that control the environment in which man lives. Therefore, the concept of Environmental protection can define as preserve and improve the environment components, prevent their degradation or pollution and reduce pollution. These components include air, sea and inland waters including the Nile River, lakes, groundwater and land, natural reserves and other natural resources.

And it determinate the competent administrative agency concerned that protection of the Water Environment; Protection of Land Environment from Hazardous Materials and Waste; protection of Air Environment From Pollution by Harmful Substances and Pollution from Sewage and Garbage.

\section{Hypotheses}

To ensure a statistically significant relationship between CSR and environmental protection from pollution in Egypt, the following hypotheses were formulated to test the assumed relationship between the search variables: 
The basic hypothesis:

H1. CSR affects the protection of the environment from pollution.

H1a. Adopting the concept of societal responsibility positively affects the protection of the environment from pollution.

H1b. The strength of the dimensions of societal responsibility positively affects the protection of the environment from pollution.

\section{Methodology}

\subsection{Questionnaire}

The questionnaires were administered to employees of petrochemical companies operating in Alexandria Governorate were managed in seven companies ((EPC) Egyptian Petrochemical Company, (SIDPEC) Sidi Kerir Petrochemicals Company, (ETHYDCO) The Egyptian Ethylene And Derivatives Company, Egyptian Linear Alkyl Benzene (ELAB) (2019) Company, Egyptian Styrenics (EStyrenics) (2019) Company, Alexandria National Refining and Petrochemicals Company (ANRPC) (2019), Alexandria Specialty Petroleum Products (ASPPC) (2019) Company during the period from October 2017 to December 2018. All locations were repeated on different days of the week to be able to cover all employees. The respondents were contacted on location through a direct and personal interview with the researcher. Before the implementation of the questionnaire, the researcher tested it through a previous sample, to verify whether the questions were clearly understood and analyze the overall degree of answers variability. Before starting the interview, the interviewer presented herself, described the purpose of the study and asked if the respondent knew about the role of their company's corporate responsibility in protecting the environment from pollution. If that was the case, that questionnaire continued until end. A sample of workers produced 134 usable questionnaires.

The questionnaire asked the respondents three following questions:

(1) The degree of adoption of the concept of societal responsibility (CSR) at your company comes through: (included seven phrases).

(2) The strength of CSR programs in your company depends on: (included five phrases).

(3) The company protects the environment from pollution when: (included seven phrases).

Furthermore, in this section the respondents expressed the extent of their agreement using a five-point Likert scale (1 - strongly disagree; 2 - disagree; 3 - neither agree nor disagree; 4 agree; 5 - strongly agree). Full details can be found in Appendix.

\subsection{Description of the sample}

The study population consisted of 1,340 managers. A cluster random sample of 134 managers was selected. Depending on the type of problem under study, the main objective of the research is to test a specific imposition of the correlation between two variables: CSR (independent variable) and environmental protection (dependent variable) (Reverse) or reverse (reverse). A review of the previous literature and its findings has led to the formulation of the research hypothesis (CSR affects the protection of the environment from pollution).

On this basis, a questionnaire was used to collect data from the sample items to test the validity or incorrect relationship between the variables in question. The significance of the 


\section{REPS}

relationship between the change in societal responsibility and environmental protection was determined during the period (s) in which the research was conducted. Based on this analysis, it is possible to determine whether the hypothesis being tested is acceptable, The Bilateral Test.

The simple linear regression model: $\left(\mathbf{Y}=\boldsymbol{\beta} \boldsymbol{\boldsymbol { }}+\boldsymbol{\beta}_{\mathbf{1}} \mathbf{x}_{\mathbf{1}}+\boldsymbol{\epsilon}\right)$ was used to test the hypothesis.

\subsection{Analytical descriptive approach}

It is concerned with studying the phenomenon as it is in reality, describing it accurately, and expressing it in:

- Qualitative: by describing the phenomenon and clarifying its characteristics; and

- Quantitative: by giving a numerical description indicating the size or size of the phenomenon or the degree of association with the phenomenon or other phenomena.

Accordingly, the role of the petrochemical companies in Alexandria Governorate, and the social responsibility programs carried out within the governorate in terms of importance, growth and requirements, and the most important characteristics and constraints and components and methods of work and developments have been described. Thus, the researcher can analyze the relationship between CSR and environmental protection from pollution in Alexandria Governorate.

The limitation of the study:

- Time: The study period was set from October 2015 until September 2018.

- Place: The study focuses on the petrochemical companies operating in Alexandria Governorate.

- Human resource: The study focuses on the employees of the petrochemical companies operating in Alexandria Governorate.

The relationship between variables (Figure 1).

Companies of the applied study:

- (EPC) Egyptian Petrochemical Company;

- (SIDPEC) Sidi Kerir Petrochemicals Company;

- (ETHYDCO) The Egyptian Ethylene and Derivatives Company;

- (ELAB) Egyptian Linear Alkyl Benzene Company;

- (EStyrenics) Egyptian Styrenics Company;

- (ANRPC) Alexandria National Refining \& Petrochemicals Company; and

- (ASPPC) Alexandria Specialty Petroleum Products Company.

Legal framework of the applied study:

Figure 1.

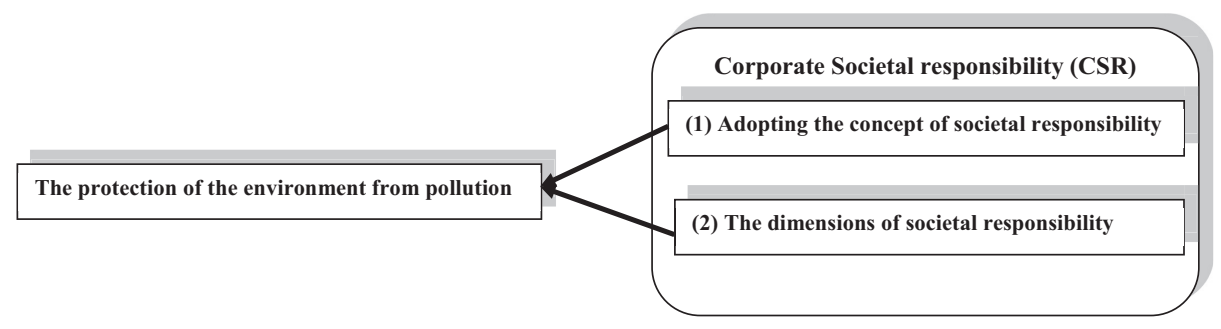


According to petrochemical companies legal Department, "Legally", The Egyptian Petrochemical Company (a public business company) is a member of the Egyptian Petroleum Sector and affiliated to the Egyptian petrochemical holding company (ECHEM), it has been established at 20/9/1981, and started production at September 1987, and the Egyptian Petrochemical Company is the first petrochemical company to produce PVC originating in the Arab Republic of Egypt.

The following companies are listed in the commercial registration (8) for the year 1997 and its amendments, which were canceled and replaced by Law (72) of 2017:

The shareholders of Sidi Kerir Petrochemicals Company are [Egyptian petrochemicals holding company (ECHEM) (20 per cent), Egyptian Petrochemicals Co. (7 per cent), Ahli Capital Holding (7 per cent), National Investment Bank (7 per cent), Government Sector Employees Trust Fund (19 per cent), Private Sector Employees Trust Fund (12 per cent), Misr Insurance Co. (3 per cent), Naser Social Bank (2 per cent) and General Public Offering (23 per cent)].

The shareholders of The Egyptian Ethylene and Derivatives Company are [Egyptian petrochemicals holding company (ECHEM) (20 per cent), SIDPEC (20 per cent), GASCO (11 per cent), Al Ahly Capital Holding (21 per cent) National Investment Bank (14 per cent), Banque Misr (10 per cent), Naser Social Bank (4 per cent)].

The shareholders of Egyptian Linear Alkyl Benzene Company [National Investment Bank (34.15 per cent), Royal Co (0.22 per cent), Ministry of Finance (13.11 per cent), EGPC (10.50 per cent), Egas (21 per cent), Egyptian petrochemicals holding company (ECHEM) (21.01 per cent)].

The shareholders of Egyptian Styrenics Company (National Investment Bank, Egyptian petrochemicals holding company (ECHEM), Ministry of finance, Petrojet, Enppi).

The shareholders of Alexandria National Refining and Petrochemicals Company [Bank of Alexandria (7.75 per cent), National Bank of Egypt (18.25 per cent), Alexandria Petroleum Company (72.99 per cent), Misr Insurance Company (0.54 per cent), Misr Life Insurance (0.47 per cent)].

The shareholders of Alexandria Specialty Petroleum Products Company [Misr Petroleum Company (12.60 per cent), Alexandria Petroleum Company (20 per cent), CO_OP Company (12.60 per cent), National Bank of Egypt (10.40 per cent), Bank Misr (10.40 per cent), Naser Social Bank (4.20 per cent), Commercial International Investment Company (5.20 per cent), Al Watany Bank of Egypt (5.20 per cent), Misr Insurance Company (5.58 per cent), Misr Life Insurance Company (4.82 per cent), Social Insurance Fund For The Government Sector (4.50 per cent), Social Insurance Fund For Public And Private Sector (4.50 per cent)].

In Egypt, petrochemical companies do not have a separate CSR department so there is no hierarchical structure entailed. They are not familiar with the term of CSR or aware of the global CSR initiatives, even though there is annual Company Report that is published on their website portal (Company Report).

The practical frame mechanisms applied by companies to enhance the idea of societal responsibility and environment protection:

\subsection{Societal responsibility}

The petrochemical companies are committed to promoting a safe, stable, supportive and productive work environment through the foundations of work and ethical, cooperative and sustainable behavior. These include the vision of petrochemical companies to promote human rights and social values through the integration of societal responsibility within their activities and that codes of conduct have a positive impact on society, rules of international 
law and standards of conduct. This is to increase the production capacity of high-quality and value added petrochemical products.

Over the past years and period of study, petrochemical companies have played a social role in developing the surrounding environment within the limits set by the General Assembly of these companies through:

- Pavement and lighting of the main road leading from and to the companies and surrounding areas, and the paving and development of railway glider.

- Contribution and permanent contribution in the field of health and medical treatment and purchase of medical devices, and contribute mainly to convoys of medical treatment and all medical supplies in public hospitals and universities.

- Contribution and permanent contribution to charitable societies in areas surrounding petrochemical companies, and provide their needs to upgrade the infrastructure of these areas, and the participation of residents of the region in various events, and donate to government schools.

- Rationalize the electricity consumption of some residential areas surrounding the companies, to save energy as part of a lower bill [...] Better life. (websites of the seven petrochemical companies).

\subsection{Environmental protection}

Petrochemical companies are oil companies engaged in the production, processing, operation, treatment, sale, purchase, import and export of final and intermediate petrochemicals, production and sale of electrical power, maintenance, water treatment and industrial drainage and doing everything related to this purpose or helping to complete it. And is committed to ensuring that all its activities are carried out in such a way that the health and safety of all its employees and others are of absolute priority in a moral and professional sense, in the belief that it is of great importance. To maintain ecological balance at the end, it is committed to:

5.5.1 Occupational safety and health activities. Petrochemical companies are committed to maintaining the safety of employees, contractors, visitors and the surrounding community, protecting the environment, preventing pollution, conserving natural resources and sustainable development. This is achieved through the adoption by senior management of the following objectives:

- continuous growth while preserving the climate conducive to attraction and retention of qualified persons in the areas of work of the company;

- support and continuous development of staff skills to ensure that the leading role in the production and supply of petrochemical materials is maintained;

- employees are the driving force must be involved and maintain their safety;

- identification of work hazards and the development of adequate means of control to ensure the safety of workers and environmental protection and efficiency of production processes;

- training and awareness of all employees in the world's largest oil and petrochemical companies and specialized scientific and research bodies;

- excellence with the interests of the surrounding society in mind and its member's safe without any damage; 
- preserving the environment is a national duty and a primary objective that the senior management seeks to achieve;

- adopting HSE principles as core values;

- compliance with all local laws and regulations and international standards;

- adherence to ethical and legal behavior;

- use the best environmental techniques and practices available to reduce emissions and waste, and to meet the expectations and demands of customers and satisfy them;

- application of occupational safety and health management systems OHSAS 18001 and environmental management ISO 14001;

- to comply with the ISO 50001 Energy Management System for the purpose of optimizing energy use and preserving natural resources; and

- documenting, distributing and monitoring all system management documents and documents to the concerned departments and communicating information related to this subject to all the employees of the company, while providing environmental data and information to the official stakeholders. (websites of the seven petrochemical companies)

\subsubsection{Energy management systems.}

5.1.2.1 Energy. The Alexandria petrochemical companies have chosen to apply one of the energy handling methods to ensure the improvement of sustainable energy efficiency and continuous improvement of performance, the "energy management system", to obtain the technical support needed to prepare and implement the requirements of the energy management system in these companies and to obtain the ISO 50001 certificate. November 2011 to be certified to comply with the international standard of energy management system 50001: 2011 to be one of the first Egyptian companies to obtain this certificate and the first among the oil and gas companies and petrochemicals in Egypt, which obtains that certificate, The support of senior management, the formation of the energy team from all disciplines, increased communication with employees and the dissemination of achievements and success stories to motivate employees to participate in the energy efficiency of the company are key factors for SEDEPC's success in implementing the energy management system (Websites of the seven petrochemical companies).

5.1.2.2 Rehabilitation program for petrochemical companies to implement the energy management system. After participating in the training program organized by the UNIDO in the framework of the project to improve industrial energy efficiency in Egypt and the success of SEDEPC in the implementation of the energy management system resulting in the ISO 50001 certificate, and it expand the exchange of knowledge and expertise acquired in the field of energy management and transfer to other companies.

UNIDO has agreed with the Egyptian Petrochemical Holding Company (ECHEM) to cooperate in the initiation of the project for the rehabilitation of companies within the petrochemical sector to implement the energy management system by supporting the national experts of SEDEPC to transfer their knowledge and expertise to the petrochemical sector in Egypt. Training and technical support were provided by SEEDBEC to 30 trainees representing six of the following petrochemical companies: EStyrenics, ELAB and ECHEM. The results of this training and technical support included 22 trainees with the "National Expert in Energy Management System from UNIDO" (Websites of Sidi Kerir Petrochemicals Company and Egyptian Petrochemical Holding Company). 
5.1.2.3 Quality. Petrochemical companies apply the concept of quality to all operations. EPC has obtained the OHSAS 18001-2007 certificate, ISO 14001-2015 certificate and the ISO 9001-2015 quality system certification certificate (Egyptian Petrochemical Company website).

While SIDPEC has been certified to comply with the requirements of ISO 9001-2015, the ISO 50001-2011 certification certificate, the 6 Sigma Black Belt certificate, the ISO 26000 compliance letter to demonstrate compliance with the requirements of ISO 26000 In the field of sustainability and societal responsibility, by receiving the National Award for Excellence from the National Institute of Quality of the Ministry of Commerce and Industry within the National Program of Excellence Awards for 2013 (Sidi Kerir Petrochemicals Company website).

ETHYDCO, in the first half of year 2018, obtained the following International Certificates: ISO 9001:2015 Certificate (Quality Management System), ISO 14001:2015 Certificate (Environmental Management System), OHSAS 18001:2007 Certificate (Occupational Safety and Health Management System), and ISO 50001:2011 Certificate (Energy Management System).

Moreover, total quality management systems general department in ETHYDCO is making great efforts to qualify the company to obtain: ISO 17025:2017 (General requirements for the efficiency of testing and calibration laboratories), and ISO 26000:2010 (Societal Responsibility). (The Egyptian Ethylene and Derivatives Company website).

ELAB entered an agreement with Energy and Environmental Studies Center, affiliate to Tebeen Institute for Metal Studies as an accredited third party to perform environmental measurements twice per year inside work environment according to Egyptian Environmental Affairs Agency, Law No. 4 ( (1994) and law no.9/2009. The periodical measurement procedures are performed by the company through environmental monitoring vehicle owned by the Petroleum Committee in Alexandria Region (Egyptian Linear Alkyl Benzene Company website).

The first area of focus in corporate societal responsibility is with regard to the environment. Other areas that considered in the development of corporate societal responsibility programs in ESTYRENICS are education, health, nutrition and employment:

Societal responsibility investment combines ESTYRENICS's financial goals with our obligation and dedication to factors that ensure the well-being of society such as environmental friendly practices, economic growth and justice in society.

Corporate societal responsibility is no longer defined by how much money ESTYRENICS contributes to charity, but by its overall involvement in activities that improve the quality of people's lives (Egyptian Styrenics Company website).

ANRPC has been accredited by Compliance Certificate for the occupational health, safety and environmental protection with honors degree, the renewal of the OHSAS18001: 2007 certification and ISO14001: 2004 certification through SGS International Company. ANRPC is committed to ongoing training systems to the safety, occupational health and environmental protection team to obtain international certifications such as: $\mathrm{NEBOH}$ certificate, certificates of various OSHA, Foam Training School Certificate, Fire Marshal certificate, NASP-OHSAS certificate 18001: 2007, ISO14001: 2004 (Alexandria National Refining and Petrochemicals Company website).

Environmental advantages of ANRPC and ASPPC products: cold applications, environmentally clean and solvent free products, safely handled and applied no harmful disposals during or after applications, energy conservation (Alexandria Specialty Petroleum Products Company website). 


\section{Results and discussion}

\subsection{Study population}

The study population consists of managers in petrochemical companies operating in Alexandria Governorate. Emphasis was placed on the Governorate of Alexandria because it is the second largest city in Egypt, and it includes seven of petrochemical companies, it is the governorate in which the researcher lives, and no other governorates were selected due to the high costs.

The Governorate of Alexandria has a number of industrial zones, which number to about nine industrial zones and thus is considered an important industrial city in the Egyptian economy. These areas are (New Borg El Arab, Nahda Industrial Zone, Mansheya Al Jadida Industrial, Nasiriyah Industrial Zone, The Agamy Small Industries Complex, the industrial ship factory area in August).

The petrochemical industry is one of the main pillars of Egypt's future economy, which is based on value added as a principle in the exploitation of natural resources. The oil sector is considered one of the sectors that has a clear vision and a specific work program for the implementation of new projects, development of existing projects, and continuous attention to the maintenance process to achieve the increase in production and the provision of direct jobs and raw materials to establish many industries that rely on petrochemical products as inputs For the productive process, and the most important projects and companies operating in the city of Alexandria:

The production of (polyvinyl chloride) (PVC) by the Egyptian Petroleum Company (EPC) is headquartered in the industrial renaissance Elnahda zone in Ameria district in Alexandria city since its establishment in 1981 with a production capacity of 80,000 tons/year using ethylene as raw material.

The production of (polyethylene) by Sidi Kerir Petrochemicals Company (SIDPEC) is headquartered in the industrial renaissance Elnahda zone in Ameria district in Alexandria city since its establishment in November 1997, a company listed on the Egyptian Stock Exchange since March 2005.

The production of (Road Emulsion, Compounded Waxes, Petroleum Jelly, Cutback and Industrial Emulsions) by Alexandria Specialty Petroleum Products Company (ASPPC) is headquartered in Wadi El-Kamar Road, Merghem, in Agami district in Alexandria city since its establishment in February 1998.

The production of (Reformate 560,000 ton/year its RONC 100, Hydrogen 33,000 t/year, Sweet LPG 12000 t/year) by (ANRPC) Alexandria National Refining and Petrochemicals Company is headquartered in Wadi El-Kamar Road, Merghem, in Agami district in Alexandria city since was established in 1999, and in September 2013, the Zero Liquid Discharge (ZLD) unit and the company's Naphtha Hydrogen Processing Unit were launched.

The production of ((LAB) Linear Alkyl Benzene, (HAB) Heavy Alkyl Benzene) by Egyptian Linear Alkyl Benzene Company (ELAB) is headquartered in Wadi El-Kamar Road, Merghem, in Agami district in Alexandria city since its establishment in November 2003.

(EStyrenics) Egyptian Styrenics Company was established in September 2005 and is headquartered in El Dekheila Port in Agami district, Alexandria city. It produces (polystyrene, styrene monomer) with a production capacity of 200 thousand tons/year from March 2009.

The production of (Linear Low and High Density Polyethylene, Polybutadiene) by the Egyptian Ethylene and Derivatives Company (ETHYDCO) is headquartered in the 
industrial renaissance Elnahda zone in Ameria district in Alexandria city since its establishment in January 2011.

Therefore the petrochemical industry is one of the most important strategic industries in Egypt. However, these companies are a source of environmental pollution, which has been monitored according to the reports of the Ministry of Environment in some industrial areas in Alexandria. The researcher seeks to show the role of societal responsibility and its application in the petrochemical companies to protect the environment from pollution in Alexandria.

\subsection{Study sample}

The study population consisted of 1,340 managers. A cluster random sample of 134 managers was selected. The sample size was determined using the equation (Agresti and Finlay, 2002, p. 148). This equation is as follows:

$$
n=\frac{N Z_{\propto / 2}^{2} \pi(1-\pi)}{\beta^{2}(N-1)+Z_{\propto / 2}^{2} \pi(1-\pi)}
$$

$\mathrm{N}=$ size of the population;

$n=$ sample size;

$Z=$ Probability value for the confidence interval of $Z$ table "normal distribution"where $Z$ at 95 per cent confidence level $=1.96$;

$\beta=$ permissible error rate $=0.05$ which is the maximum allowed statistically; and

$\pi=$ the percentage of the sample of the society which is the maximum allowed statistically $=50$ per cent (Table I).

\subsection{The variables of the study}

Table II shows the variables of the study in accordance with the recent studies and literature of the CSR criteria. They are the determinants of societal responsibility, the power of societal responsibility, the degree of awareness and commitment to societal responsibility as independent variables, and the societal responsibility and the protection of the environment from pollution as variables affiliate.

Despite the possibility of other elements to identify the criteria of societal responsibility adopted by industrial companies in general and petrochemical companies in Alexandria in particular, but the researcher was limited to the elements specified in the list of the survey as it includes the standards used in the previous studies that were reviewed in advance by the researcher and what prompted them to quote and guide them.

Table I.

Distribution of study population and study 6 sample for 2017

\begin{tabular}{llcc}
\hline$N$ & Companies & Study population & Study sample \\
\hline 1 & Egyptian Petrochemical Company & 450 & 45 \\
2 & Sidi Kerir Petrochemicals Company & 150 & 15 \\
3 & The Egyptian Ethylene And Derivatives Company & 150 & 15 \\
4 & (ELAB) Egyptian Linear Alkyl Benzene Company & 150 & 15 \\
5 & Egyptian Styrenics Company & 150 & 15 \\
6 & Alexandria National Refining and Petrochemicals Company & 150 & 15 \\
7 & Alexandria Specialty Petroleum Products Company & 140 & 14 \\
\hline
\end{tabular}




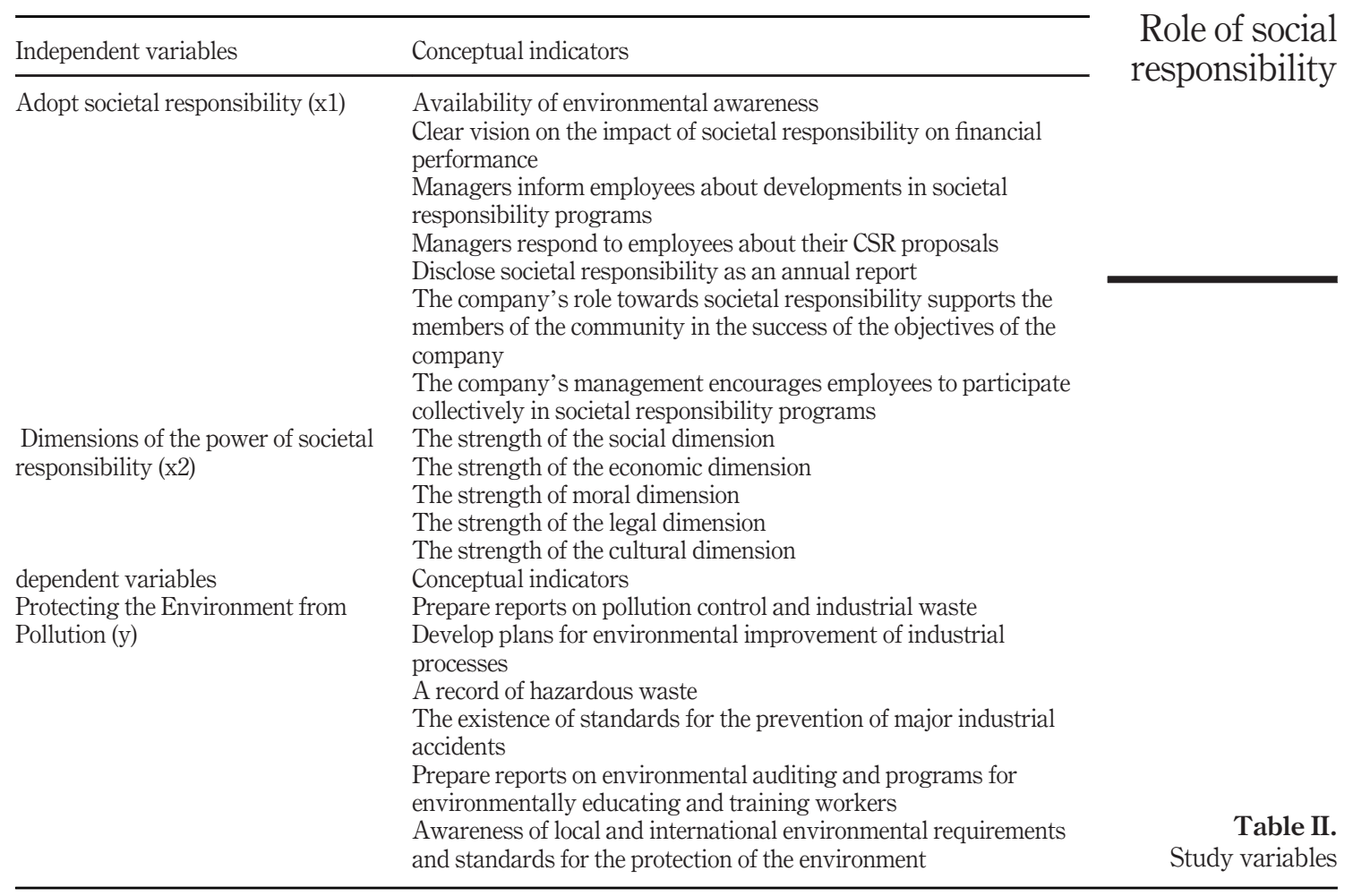

\subsection{Sources of data acquisition}

The applied study on data collection was based on primary sources through a survey list, which is the main measuring instrument and was designed to cover all the variables of the study.

\subsection{Methods of data collection}

The researcher relied on the use of the survey list in collecting the data needed to conduct the field study, in addition to conducting some personal interviews for the managers to verify the validity of the information contained in the questionnaires after collection and to obtain any other information that would be useful for the field of study. The researcher measured the variables of the study, which included (18) phrases for each of the variables that are performed in companies that adopt the concept of societal responsibility to protect the environment from pollution using the (Likert scale), which is one of the most widely used measurements Reviews for easy to understand and balance grades where individuals subject refers to test the extent of their approval of each of the statements that make up the proposed trend scale.

The responses were translated as follows:

\begin{tabular}{ccccc}
\hline I fully agree & I agree & neutral & disagree & I absolutely disagree \\
5 & 4 & 3 & 2 & 1 \\
\hline
\end{tabular}




\section{REPS}

The survey form is designed for the main categories in the companies (the general manager, the manager of the department, the production supervisor and the production worker). The survey form consists of (18) paragraphs distributed as follows:

- adopting societal responsibility and expressed in (7) phrases;

- the strength of societal responsibility and expressed in (5) phrases; and

- protection of the environment from pollution and expressed in (6) phrases.

After the researcher formulated the paragraphs of the list in its initial form, the truth was verified through content validity.

The validity of the content was verified by arbitrating this form before it was distributed by the faculty members from the administrative and statistical departments to benefit from their knowledge and knowledge curve, which earned them an outstanding reputation in their specialties, which made the form more accurate and objective in the measurement. Arbitrators all the observations mentioned have been taken into consideration.

The reliability of the parameters used by the Cronbach alpha method has been verified. The Cronbach alpha method is based on the consistency of the individual performance from one paragraph to another, indicating the strength of the correlation between the scales of the scale and, in general, of the correct one as the degree of consistency and consistency increases.

The researcher also used the method of direct contact through personal interviews with the officials of the sectors and the main departments of the companies under study, and was handed over (120) form by hand to the surveyed groups, has been clarified and understood and explained the nature and objectives of the survey and was followed up again until it was completed Table III shows the number of distributed lists, the number of recovered and correct lists and the response rate.

It is clear from the previous table that the number of survey able inspection lists (100) at a response rate is 83 per cent of the total survey lists that have been distributed and this ratio is fairly high.

\subsection{Methods of statistical analysis and hypothesis testing}

To achieve the objectives of the study, the primary data collected through the survey tool using the computer was analyzed through the program of statistical packages for social sciences (SPSS), No. 23, to test the type and strength of the relationship between the variables and to verify the difference between the independent variables The researcher used the appropriate statistical methods to analyze the results of the survey. The analysis was done on three levels.

Level 1: Evaluation of honesty and consistency in the standards used

- Verification of honesty; and

- Cronbach's alpha coefficient to confirm the degree of stability of the scale used to measure the variables of the study.

Table III.

Distributed and retrieved lists and response rate

\begin{tabular}{lccc}
\hline Statement & No. of distributed lists & No. of recovered and sound lists & Response rate $(\%)$ \\
\hline Petrochemical companies & 120 & 100 & 83 \\
\hline
\end{tabular}


Level 2: descriptive statistics

- Using descriptive methods: The results of the study were calculated to determine the extent to which the sample variables supported the availability of the variables of the study and the standard deviation to identify the extent of variance in the responses of the sample items (the respondents), the percentages and the difference coefficients.

Level 3: Testing the study hypotheses

- Using simple liner regression method: This method helps determine the relative importance of the independent variable in its effect on the dependent variable.

First, to test the validity and accuracy of the measurements used in measuring the variables of the study based on the Cronbach's alpha coefficient, this method calculates the mean correlation coefficients for all variables. The results of the study showed that all measurements were reasonably reasonable for stability, (Sekaran, 2003, P. 245). The results of the study showed that all measurements were fairly reasonable. Table IV presents the results of these tests.

Table IV shows the following:

(1) All alpha coefficients for stability are greater than 0.60 indicating the high internal consistency of the scale and thus the stability of the scale.

(2) The highest stability coefficient for the dimensions of the list is (0.91) related to the variable of environmental protection from pollution, while noting that the minimum value of stability was (0.82) of the variable dimensions of societal responsibility. Generally, the transactions show the stability of the results that can result from the survey list applied, previous analysis standards are true and consistent and this means the validity of standards and their validity to collect data.

\subsection{Descriptive analysis}

For data, the researcher used the arithmetical averages, standard deviations and variance coefficients as shown in Table V.

The above table shows that the variable of societal responsibility was the most influential in companies operating in the petrochemical sector with an average score of (3.90)

\begin{tabular}{|c|c|c|c|c|c|c|}
\hline$N$ & Dimensions & $\begin{array}{c}\text { Phrase numbers in the } \\
\text { survey list }\end{array}$ & $\begin{array}{l}\text { No. of } \\
\text { phrases }\end{array}$ & $\begin{array}{c}\text { Stability } \\
(\alpha)(\%)\end{array}$ & $\begin{array}{l}\text { Honesty } \\
(\%)\end{array}$ & $\begin{array}{l}\text { Table IV. } \\
\text { The degree of } \\
\text { stability of the }\end{array}$ \\
\hline 1 & Adopt societal responsibility $\left(\mathrm{x}_{1}\right)$ & $(1-7)$ & 7 & 71 & 84 & measurements used \\
\hline 2 & Dimensions of societal responsibility $\left(\mathrm{x}_{2}\right)$ & $(8-12)$ & 5 & 68 & 82 & to measure the \\
\hline 3 & Environmental Protection from Pollution $\left(\mathrm{y}^{3}\right)$ & $(13-18)$ & 6 & 82 & 91 & variables studied \\
\hline
\end{tabular}

\begin{tabular}{|c|c|c|c|c|c|c|}
\hline$N$ & Variables & SMA & $\begin{array}{l}\text { Standard } \\
\text { deviation }\end{array}$ & $\begin{array}{l}\text { Coefficient of } \\
\text { variation( } \%)\end{array}$ & Ranking & \\
\hline 1 & Adopt societal responsibility $\left(\mathrm{x}_{1}\right)$ & 3.9 & 0.288 & 5.85 & The first & Order of the \\
\hline 2 & Dimensions of societal responsibility $\left(\mathrm{x}_{2}\right)$ & 4.3 & 0.446 & 10.37 & The second & importance of study \\
\hline 3 & Environmental protection from pollution (y) & 3.34 & 0.825 & 24.70 & The third & variables \\
\hline
\end{tabular}


and a standard deviation of ( 0.228$)$ and a difference coefficient of (5.85 per cent) which shows the low dispersion in the responses of the sample of the study sample, (0.306) with a difference coefficient of (10.37 per cent). Finally, the variable environmental protection from pollution is calculated with a mean (3.34) and a standard deviation (0.825) with a difference coefficient of (24.70 per cent).

\subsection{Test assignments}

The researcher examined the main hypotheses of the study and focused on testing the acceptance or rejection of the study hypotheses through the use of simple regression model.

The researcher examined the main hypothesis of "CSR affects the protection of the environment from pollution". And focus on testing the acceptance or rejection of the study hypotheses through the use of simple regression model and derived from the main hypothesis sub-assumptions:

The first sub-hypothesis: "The adoption of societal responsibility positively affects the protection of the environment from pollution".

The first sub-hypothesis validity test: Table VI shows the results of the simple regression analysis test for the effect of societal responsibility on protecting the environment from pollution.

At the beginning, we evaluated and impact of adopting the concept of corporate societal responsibility to protect the environment from pollution. The aim of this procedure was to know whether environmental issues and environmental protection from pollution in petrochemical companies are related to the extent of adoption of the concept of societal responsibility.

For the statistical analysis, we set the hypothesis, "The adoption of societal responsibility positively affects the protection of the environment from pollution". The analysis was carried out via discrimination of statistical hypothesis: There is no positive effect to adopt societal responsibility to protect the environment, or there is a positive impact to the adoption of societal responsibility to protect the environment.

The results of the first sub-hypothesis test: The figures in Table VI show the regression model estimates of the relation between the variable of the adoption of societal responsibility as an independent variable and the variable protection of the environment from pollution as a dependent variable.

- The impact of the adoption of societal responsibility to protect the environment from pollution.

- The results of the statistical analysis showed that there is a significant effect of societal responsibility on protecting the environment from pollution. The correlation coefficient reached 0.92 at a significant level of 1 per cent. This means that there is a

\section{Table VI.}

Simple regression analysis results of the effect of societal responsibility on protecting the environment from pollution

\begin{tabular}{|c|c|c|c|c|c|c|}
\hline Statement & $R$ & $R^{2}$ & $\mathrm{~F}$ test & Sig & Variables & $\begin{array}{l}\beta \\
\text { Regression coefficient }\end{array}$ \\
\hline $\begin{array}{l}\text { Protecting the } \\
\text { environment from } \\
\text { pollution (y) }\end{array}$ & 0.92 & 0.85 & 545.36 & $\begin{array}{l}0.000 \\
0.000\end{array}$ & $\begin{array}{l}\text { Constant } \\
\text { Adopt societal } \\
\text { responsibility }\left(\mathrm{x}_{1}\right)\end{array}$ & $\begin{array}{l}1.004 \\
0.763\end{array}$ \\
\hline \multicolumn{7}{|c|}{ Note: ${ }^{* *}$ Significant level at $1 \%$} \\
\hline
\end{tabular}


significant positive correlation between the variable of societal responsibility and variable Protect the environment from pollution.

- The coefficient of $R^{2}$ determination is (0.85), meaning that 0.85 of the changes in the environmental protection variable from pollution are due to the variable of societal responsibility and 15 per cent due to other factors. Therefore, this model is characterized by quality. The independent variable selected explains about 85 per cent of the changes Occur in the dependent variable (environmental protection from pollution).

- In finding that the value of the effect of the coefficient of societal responsibility $(\beta)$ is (0.763). This means that the increase in one degree in $\left(\mathrm{x}_{2}\right)$ leads to an increase in the environmental protection variable from pollution by $(0.763)$.

- The value of $\mathrm{F}$ is calculated at 545.36. The significance of this effect is the calculated value of $\mathrm{F}$ (545.36), which is significant at sig $=0.000$.

- Positive reference coefficient of independent variable regression Adopted societal responsibility $\left(\mathrm{x}_{2}\right)$ with the dependent variable environmental protection from pollution (y).

- This means acceptance of this hypothesis, and the ability of this variable to contribute to the interpretation of the change in the protection of the environment from pollution, and therefore we reject the zero hypothesis and accept the alternative hypothesis.

According to the previous result, we find that petrochemical companies adopt the concept of societal responsibility, as a result of the following:

- clear vision on the impact of societal responsibility on financial performance;

- the environmental awareness of senior leadership and employees;

- managers should inform employees about the latest developments in societal responsibility programs;

- the company's role towards societal responsibility supports the members of the community in the success of the objectives of the company;

- transparency in the presentation of data by disclosing the company's societal responsibility programs as an annual report;

- the company's management encourages employees to participate collectively in societal responsibility programs; and

- managers respond to employees about their CSR proposals.

This will lead the petrochemical companies to respond to the requirements of its social environment, the rights of the community, and the interests of their stakeholders in making decisions. Petrochemical companies must take actions on the effects of the decisions on all stakeholders of society. Making balance between their interests and the interests of the beneficiaries, which is ultimately protects the environment from pollution. This finding is consistent with the study of Hawrysz and Foltys (2015), Andrei et al. (2014), Al-Tira (2012), Bhagwat (2011) and Tiwari (2010).

The second sub-assumption: "The dimensions of societal responsibility positively affect the protection of the environment from pollution".

The Second sub-hypothesis validity test: Table VII shows the results of the simple regression analysis test of the impact of societal responsibility dimensions on environmental protection from pollution. 


\section{REPS}

The researcher evaluated and impact of the dimensions of societal responsibility to protect the environment from pollution. The aim of this procedure was to know whether environmental protection from pollution in petrochemical companies are linked to the impact of societal responsibility dimensions, and the extent to which these dimensions influence them.

For the statistical analysis, we set the hypothesis, "The dimensions of societal responsibility positively affect the protection of the environment from pollution". The analysis was carried out via discrimination of statistical hypothesis: There is no positive effect to the dimensions of societal responsibility to protect the environment, or: There is a positive impact to the dimensions of societal responsibility to protect the environment.

The results of the second sub-hypothesis test are shown from the figures in Table VII to the regression model estimates of the relationship between the variable of societal responsibility dimensions as an independent variable and the variable protection of the environment from pollution as a dependent variable.

The impact of the dimensions of societal responsibility on the protection of the environment from pollution.

The results of the statistical analysis showed that there is a significant effect of societal responsibility on protecting the environment from pollution. The correlation coefficient reached 0.85 at a significant level of 1 per cent. This means that there is a strong correlation between significance variable and variable protect the environment from pollution:

- The coefficient of $R^{2}$ determination is 0.72 , meaning that 0.72 of the changes in the environmental protection variable from pollution are due to the variable of societal responsibility dimensions and 26 per cent are due to other factors. Therefore, this model is characterized by quality. The selected independent variable explains about 72 per cent which occur in the dependent variable (environmental protection from pollution).

- In finding that the value of the degree of influence of the social liability dimension $(\beta)$ is $(0.638)$. This means that the increase in one degree in the dimensions of societal responsibility leads to an increase in the protection of the environment from pollution by 0.638 .

- The value of $\mathrm{F}$ is calculated at 267.99. The significance of this effect is the calculated value of $\mathrm{F}(267.99)$, which is significant at ( $\mathrm{sig}=0.000)$.

- Positive reference coefficient of independent variable regression societal responsibility dimensions with dependent variable Environmental protection from pollution.

- This means acceptance of this hypothesis, and the ability of this variable to contribute to the interpretation of the change in the protection of the environment

Table VII.

Simple regression analysis results of the impact of societal responsibility dimensions on environmental protection from pollution

\begin{tabular}{lccccccc}
\hline & & & & & & & \\
Statement & $R$ & $R^{2}$ & F test & Sig & Variables & $\begin{array}{c}\text { Regression } \\
\text { coefficient }\end{array}$ \\
\hline $\begin{array}{l}\text { Protecting the environment from } \\
\text { pollution (y) }\end{array}$ & 0.85 & 0.72 & 267.99 & 0.000 & $\begin{array}{l}\text { Constant } \\
\text { Dimensions of societal } \\
\text { responsibility }\left(\mathrm{x}_{2}\right)\end{array}$ & 1.004 \\
& & & & 0.000 & 0.763
\end{tabular}


from pollution, and therefore we reject the zero hypothesis and accept the alternative hypothesis.

According to the previous result, we find that the dimensions of societal responsibility which affecting the work programs of petrochemical companies are:

- the strength of the economic dimension;

- the strength of the cultural dimension;

- the strength of the legal dimension;

- the strength of moral dimension; and

- the strength of the social dimension.

Our results confirm that strategic CSR is contingent to financial performance, befitting its role as the basic economic unit in a market economy; the first and foremost societal responsibility must be economic in nature. As a basic economic unit in society, the economic dimension of a corporation's social behavior extends to the production of goods and services demanded by society and available to them at reasonable and acceptable profit. The primacy of this dimension of CSR is based upon the fact that all other societal responsibilities borne or expected of a business are predicated on this fundamental obligation. This finding is consistent with the study of McWilliams and Siegel (2011).

The second ranking of the impact of the strength of the dimensions of corporate societal responsibility on protect the environment from pollution in the petrochemical companies is the cultural dimension, societal responsibility is an organizational culture that must be disseminated among the employees of the company. It is to respect human rights, support cultural development, spread commitment to the laws and regulations of the society, promote national culture and cultural communication locally, regionally and globally and support cultural and civilizational activities (Halkos and Skouloudis, 2016).

The third ranking of the impact of the strength of the dimensions of corporate societal responsibility on protect the environment from pollution in the petrochemical companies is the legal dimension, because businesses must operate within the legal framework in achieving their business objectives (Mohammed and Rashid, 2018).

The fourth ranking of the impact of the strength of the dimensions of corporate societal responsibility on protect the environment from pollution in the petrochemical companies is the moral dimension, there are some elements of business behavior and activities cannot necessarily be codified into the regulatory frame, are unwritten and is an implicit social contract that businesses have with society and often acts as the source and base for extensions into the explicit social contracts embodied and codified in the formal legal framework, society has expectations of business to exhibit social behavior over and above the mandatory requirements imposed on them (Trevino and Nelson, 1999).

The fifth ranking of the impact of the strength of the dimensions of corporate societal responsibility on protect the environment from pollution in the petrochemical companies is the social dimension, this dimension refers to relationship between all types of organizations and society in general (Currás-Pérez et al., 2017).

This finding is consistent with the study of Stojanovic et al. (2016), Zanat (2016), Mohamed Arfa (2015), Abu-Halaqan (2014), Muller and Kolk (2012), Elmore (2011), Sajib et al. (2011). 
Results

General results

- There is paucity in the studies that dealt with the relationship between CSR and environmental protection against pollution in public organizations.

- There is agreement among the sample on the importance and feasibility of adopting the concept of societal responsibility and placing it at the top of the top management concerns, especially in the field of petrochemical companies. With the need to take concrete implementation measures to support societal responsibility programs aimed at serving the community among all stakeholders.

- The effective implementation of the mechanisms for the implementation of meaningful societal responsibility programs requires fundamental changes in management practices, existing organizational structures and the quality of personnel working in the relevant departments in general and the societal responsibility group in particular, which may be difficult for political and economic reasons.

\section{Results of the applied study}

(1) The adoption of societal responsibility positively affects the protection of the environment from pollution, and this effect shows that the adoption of the concept of Corporate societal responsibility is influenced by the following factors:

- increasing the participation of workers with healthy environmental contributions to the productive process;

- increasing the capacity of companies to cope with disasters and environmental crises;

- increased commitment of companies to implementing environmental public policies;

- increasing the companies' economic and social activities towards protecting the environment from pollution;

- increasing the capacity of companies to pay greater costs to preserve the environment;

- increasing the awareness of green consumers with the products provided by companies;

- development of continuous internal work environment companies; and

- clearly defined strategy followed in societal responsibility programs.

(2) The societal responsibility of the public organizations derives their strength through:

- The keenness of these organizations to analyze the variables of the ethical dimension of societal responsibility and their availability, which will lead the organizations to provide their services with the highest quality and sincerity. And that this analysis [(ethics of individuals) as training members of the societal responsibility team to solve problems using brainstorming and provide employees with official data related to improving work, (Ethics of leadership), such as the identification of business objectives through the participation of managers with subordinates, and the punishment of workers who exhibit immoral behaviors (ethics of productive processes) as a decision-making process to ethical standards regardless of the costs involved. When there is an 
immoral behavior and managers are responsible for implementing the changes needed to reach the targeted outcomes];

- Promote partnerships with other relevant sectors for community service;

- Align the mission and objectives of the organization with the goals and values of the community in which it operates;

- Ensure compliance with legislation and laws that urge organizations to increase transparency and disclosure while providing incentives for the distinction of working organizations In the area of societal responsibility and environmental protection; and

- To develop an integrated strategy for the culture of the organization on the societal responsibility programs to be provided by the organization by applying and practicing the work ethic to protect the environment from pollution on the other to motivate the workers to practice the best behavior towards work and to participate in training programs to disseminate the principles of work ethic and culture of societal responsibility among them, Giving them better opportunities to develop their skills and experience and enhance their motivation to work.

(3) Petrochemical companies, especially public and private sector companies, produce goods and products in an environmentally friendly manner, taking into consideration waste recycling and wastewater treatment, continuous monitoring of any type of radiation or emission of harmful gases such as carbon dioxide. Such treatment should not be limited to guidance from before the EEAA or by the sovereign agencies of the state or under the pressure of laws, but must be paying attention to the development of the educational axis and support the educational aspect constantly.

(4) Although all CSR programs within Egypt are philanthropic and humanitarian, there is still a difference between the nature of these programs offered by the public sector companies and the government sector for the private sector companies, especially in the field of environmental protection against pollution. Therefore, these efforts should be consolidated through the work of partnerships directed by the private sector towards the social imbalance that is required to be reformed.

\section{Recommendations of the study}

According to the results of the previous studies and the applied study results, the researcher would like to submit a mechanism to the directors and heads of the boards of directors of the Egyptian petrochemical companies under study:

- increase the participation of workers with healthy environmental contributions in the production process and increase the ability of companies to cope with disasters and environmental crises;

- increase the commitment of companies to implement environmental public policies and guide their economic and social activities towards protecting the environment from pollution;

- increase the capacity of companies to bear greater costs to preserve the environment and increase the awareness of the green consumer with the products provided by companies; 
- develop the internal work environment of companies with a clear definition of the strategy followed in societal responsibility programs;

- the organizations' keenness to analyze the variables of the ethical dimension of societal responsibility and training the members of the team on societal responsibility to solve problems using brainstorming;

- encourage other relevant companies to serve the community; and

- develop an integrated strategy for the culture of the organization on the programs of societal responsibility to protect the environment from pollution and interest in involving staff in training programs to disseminate the principles of ethics.

\section{Conclusion and future studies}

The issue of societal responsibility and ethical aspects is of great importance at the present time due to the increasing influence of organizations and the increasing criticism directed at them in aspects related to the legitimacy of its work and mechanisms such as cases of corruption and unethical decisions affecting society and the environment. With the increasing role of business organizations in civil society and lobbying groups because of the spread of knowledge and the speed of communication, government organizations are obliged to enhance their social performance, especially petrochemical companies, to many community groups. All these issues have forced the management of governmental and private organizations to broaden the perspective through which they see their social role and their humanitarian performance toward different segments of society.

Finally, regarding future research lines, it would be very interesting to examine the proposed model by collecting data from a significantly large source and examining the hypothesized relationships, and it would also be very useful to analyze alternative channels of influence of legal form and environmental policy on the protection of the environment in oil and gas companies.

\section{References}

Abu-Halaqan, E.S. (2014), “The impact of the organization on the concept of social responsibility on the degree of customer satisfaction - applied study", M. Thesis, Sadat academy for administrative sciences, Faculty of administrative sciences, Alexandria, p. 133.

Agresti, A. and Finlay, B. (2002), Statistical Methods for Social Sciences, 2nd ed., Palgrave Macmillan, New York, NY, p. 148.

Al-Maazawy, A.F. (2004), "The role of EEAA in solving administrative and legal problems in Egypt an analytical study in managing environmental problems", M. thesis, Sadat Academy for Administrative Sciences, Alexandria, p. 8.

Al-Tira, K. (2012), "The impact of management and employees' awareness of the social responsibility of the organization on the competitive advantages of applied industry in libya”, Ph. D. thesis, Ain Shams University, Faculty of Commerce.

Amaeshi, K., Adegbite, E. and Rajwani, T. (2016), "Corporate social responsibility in challenging and non-enabling institutional contexts: do institutional voids matter?", Journal of Business Ethics, Vol. 134 No. 1, pp. 135-153.

Andrei, J., Panait, M. and Ene, C. (2014), "Environmental protection between social responsibility, green investments and cultural values", Faculty of Economic Sciences, Petroleum-Gas University of Ploiesti, Romania, MPRA Paper No. 60189, pp. 2-8. 
Arafa, A.M. (2015), "Ethical responsibility and its role in empowering Employees - a field study on application to international industrial companies in 10th of ramadan city", Supplementary Research, Suez Canal University, Faculty of Commerce.

Alexandria (2019), National Refining and Petrochemicals Company (ANRPC) available at: www.anrpc. com

Alexandria Specialty Petroleum Products Company (ASPPC) available at: www.asppc.com.eg

Barrow, C.J. (2000), Developing the Environment: problems and Management, Longman Limited, New York, NY, p. 25.

Berger-Walliser, G. and Scott, I. (2018), "Redefining corporate social responsibility in an era of globalization and regulatory hardening", American Business Law Journal, Vol. 55 No. 1, pp. 167-218.

Bhagwat, P. (2011), "Corporate social responsibility and sustainable development”, Conference on Inclusive and Sustainable, Growth Role of Industry, Government and Society Conference Proceedings, pp. 1-13.

Cameron, R. (2009), "Community and government effect on CSR: Case studies of mining on bolivia's altiplano", M. thesis, Saint Mary's University, p. 1.

Carroll, A.B. (1999), “Corporate social responsibility: evolution of a definitional construct”, Business and Society, Vol. 38 No. 3, p. 70.

Currás-Pérez, R., Dolz-Dolz, C., Miquel-Romero, M.J. and Sánchez-García, I. (2017), "How social, environmental, and economic CSR affects consumer-perceived value: does perceived consumer effectiveness make a difference?", Faculty of Economics, Department of Marketing, University of Valencia, Valencia, pp. 733-744.

Egyptian Environmental Affairs Agency, Law No. 4 (1994), "On the protection of the environment and its executive regulations, general provisions of the egyptian environmental law”, p. 3.

Egyptian Linear Alkyl Benzene (ELAB) (2019), available at: www.elab-eg.com

Elmore, T. (2011), "Promoting ethical behavior among local government employees the role of ethical leadership, ethics code training and audits", PH. D thesis, KS City, MO, pp. 162-165.

Environmental Protection Agency (2013), "Environmental protection through research", An Ghníomhaireacht um Chaomhnú Comhshaoil, p. 11.

Egyptian Petrochemical Company (EPC) (2019), available at: www.egy-petrochem.com

Egyptian Styrenics Company (EStyrenics) (2019), available at: http:/estyrenics.com

The Egyptian Ethylene and Derivatives Company (ETHYDCO) >available at: www.ethydco-eg.com

Freeman, R.E. (1984), Strategic Management a Stakeholder Approach, Pitman, Boston.

Frynas, J.G. and Yamahaki, C. (2016), "Corporate social responsibility: review and roadmap of theoretical perspectives", Business Ethics: A European Review, Vol. 25 No. 3, pp. 258-285.

Halkos, G. and Skouloudis, A. (2016), "Cultural dimensions and corporate social responsibility: a cross-country analysis", Centre for Environmental Policy and Strategic Environmental Management, Department of Environment, University of the Aegean, MPRA Paper No. 69222, pp. 7-15.

Hamilton, C. and Bastianoni, S. (2019), "Environmental protection and ecology", Encyclopedia of Ecology, Vol. 4, 2nd ed., pp. 319-326.

Hawrysz, L. and Foltys, J. (2015), Environmental Aspects of Social Responsibility of Public Sector Organizations, Department of Organization and Management, Faculty of Economy and Management, Opole University of Technology, Opole, pp. 1-8.

ISO 26000 (2007), "Working group on social responsibility: working definition”, Sydney, available at: www.afnor.org (accessed 1 October 2015). 
Jamali, D., Lund-Thomsen, P. and Jeppesen, S. (2017), "SMEs and CSR in developing countries", Business and Society, Vol. 56 No. 1, pp. 11-22.

Jammulamadaka, N. (2018), "Reading institutional logics of CSR in India from a post-colonial location", Journal of Business Ethics, pp. 1-19.

Jensen, M.C. and Meckling, W.H. (1976), "Theory of the firm: managerial behavior, agency costs and ownership structure", Journal of Financial Economics, Vol. 3 No. 4, pp. 305-360.

Kolk, A. and Lenfant, F. (2010), "MNC reporting on CSR and conflict in Central Africa", Journal of Business Ethics, Vol. 93 No. S2, pp. 241-255.

Letmathe, P. and El-Bassiouny, D. (2019), "Political instability and corporate social responsibility: the case of Egypt", Social Responsibility Journal, pp. 6-14.

Lockett, A. and Thompson, S. (2004), "Edith penrose's contributions to the resource-based view: an alternative perspective", Journal of Management Studies, Vol. 41 No. 1, pp. 193-203.

McWilliams, A. and Siegel, D. (2011), "Creating and capturing value: strategic corporate social responsibility: resource-based theory, and sustainable competitive advantage", Journal of Management, Vol. 37 No. 5, pp. 1480-1495.

Marquis, C. and Raynard, M. (2015), "Institutional strategies in emerging markets", Academy of Management Annals, Vol. 9 No. 1, pp. 291-335.

Mohammed, A. and Rashid, B. (2018), "A conceptual model of corporate social responsibility dimensions, brand image, and customer satisfaction in Malaysian hotel industry", Kasetsart Journal of Social Sciences, Vol. 39, pp. 358-364.

Muller, A. and Kolk, A. (2012), "Responsible tax as corporate social responsibility: the case of multinational enterprises and effective tax in India", Business and Society, pp. 21-23.

Mustafa, M.A. (2013), "Social responsibility and its impact on corporate financial performance", M. Thesis, Cairo University, Faculty of Economics and Political Science, p. 120.

Othman, A.I. (1999), "Disclosure of social responsibility information for economic Unity", Journal of the Faculty of Commerce for Scientific Research, Vol. 36 No. 2, pp. 9.

Pfeffer, J. and Salancik, G.R. (1978), The External Control of Organizations: A Resource Dependence Perspective, Harper and Row, New York, NY.

Platonova, E., Asutay, M., Dixon, R. and Mohammad, S. (2018), "The impact of corporate social responsibility disclosure on financial performance: evidence from the GCC Islamic banking sector", Journal of Business Ethics, Vol. 151 No. 2, pp. 451-471.

Reverte, C. (2009), "Determinants of corporate social responsibility disclosure ratings by Spanish listed firms", Journal of Business Ethics, Vol. 88 No. 2, pp. 351-366.

Rugman, A.M. and Verbeke, A. (2002), "Edith Penrose's contribution to the resource-based view of strategic management”, Strategic Management Journal, Vol. 23 No. 8, pp. 769-780.

Sajib, Q.U., Rajib, S.U. and Alam, S. (2011), An Assessment on the Adaptation of ISO 14000 in the Fertilizer Industry of Bangladesh for the Sustainable Development, Wuhan University of Technology, School of Management, pp. 2480-2488.

Sekaran, U. (2003), Research Methods for Business: A Skill-Building Approach, 4th ed., John Wiley and Sons, Macmillan, New York, NY, p. 245.

Scott, R.W. (2001), Institutional and Organizations, 2nd ed., Sage Publications, Thousand Oaks.

Sidi Kerir Petrochemicals Company (SIDPEC) (2019), available at: ar.sidpec.com

Stojanović, A., Mihajlović, I. and Schulte, P. (2016), "Corporate social responsibility: Environmental aspects", International May Conference on Strategic Management, Bor, PP. 1-14.

Suchman, M.C. (1995), "Managing legitimacy: strategic and institutional approaches", The Academy of Management Review, Vol. 20 No. 3, pp. 571-610.

The Egyptian Environmental Protection Law (2009), available at: www.eeaa.gov.eg 
The Institute of Company Secretaries of India (ICSI) (2005), "Material”, p. 301. published by Company Secretaries of India.

Tiwari, N. (2010), Environment Protection and Corporate Social Responsibility: A Critique from Legal Perspective, Faculty of Law, Banaras Hindu University, Varanasi, PP. 1-7.

Trevino, L. and Nelson, K. (1999), Managing Business Ethics, Straight Talk about How to Do It Right, 2nd ed., John Wiley and Sons, New York, NY.

Wagner, T.P. (1994), A Guide to Understanding Pollution and Its Effect, Thomson Publishing Inc., Canada, P. 20.

Zanat, S. (2016), "The role of environmental taxes and fees in guiding the environmental behavior of the economic institution in Algeria", M. Thesis, University of Mohamed Boudeif Bamsila, Faculty of economic and commercial sciences and management sciences.

Zhang, J., Cheng, M., Wei, X., Gong, X. and Zhang, S. (2019), "Internet use and the satisfaction with government environmental protection: evidence from China", Journal of Cleaner Production, Vol. 212, pp. 1025-1035. Volume P.

\section{Further reading}

Daibis, M.Y. (1997), "Environmental pollution and the challenges of survival: an anthropological perspective", Series of Anthropology and Community Issues, Alexandria, p. 15.

World Bank Group (2015), "Egypt, Arab rep”, available at: http://data.worldbank.org 


\section{The survey method}

Please read each of the following statements carefully to determine the degree of your agreement or disagree of any of them by marking in a position that largely reflects your personal opinion of the term.

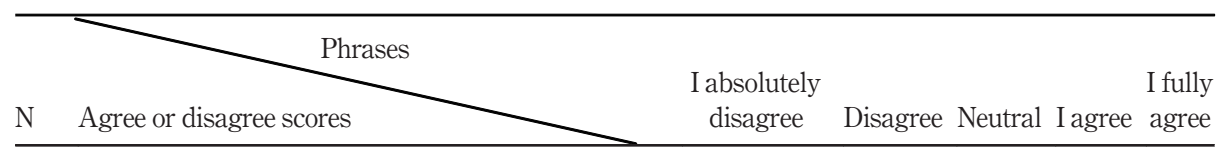

The degree of adoption of the concept of societal responsibility (CSR) at the company comes through:

1 Availability of environmental awareness

2 Clear vision on the impact of societal responsibility on financial performance

3 Managers inform employees about developments in societal responsibility programs

4 Managers respond to employees about their CSR proposals

5 Disclose societal responsibility as an annual report

6 The company's role towards societal responsibility supports the members of the community in the success of the objectives of the company

7 The company's management encourages employees to participate collectively in societal responsibility programs

The strength of CSR programs depends on:

1 The strength of the social dimension. When the company performs its business and services with high quality and energy efficiency through the use of modern technology in product design, providing raw materials, reducing pollution and waste and maintaining environmental balance

2 The strength of the economic dimension. When the company preserves natural resources and rationalizes their consumption by setting a clear environmental policy and linking the analysis of environmental and social role and the proper environmental contribution to production processes

3 The strength of moral dimension. When the company maintains the rights of the community through a clear vision of the concept of societal responsibility and the dissemination of environmental culture among its employees of the company and protection of the environment from the effects of industrial waste and committed to honesty in all business dealings in ways that are clear and non-twisted

4 The strength of the legal dimension. When the company's commitment to local laws in the course of its activities through the dissemination of a culture of adherence to the laws and regulations in the society, support and respect for human rights

Table AI. declared globally and the establishment of legal 


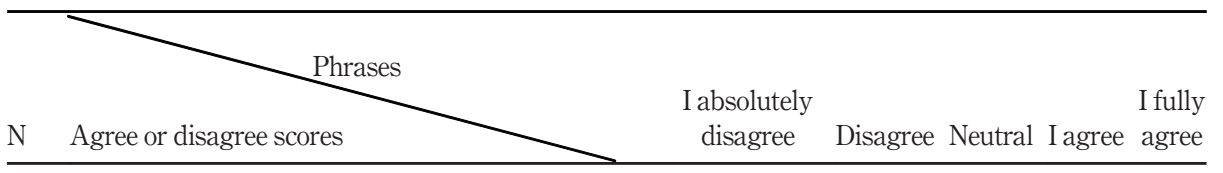

entities (units, departments) whose task is to work according to the system of institutions sponsoring the concept of societal responsibility

5 The strength of the cultural dimension. When the company develops environmental and social awareness among customers and suppliers by organizing awareness campaigns on the importance of the environment and implementing programs to protect and preserve the environment

The company protects the environment from pollution when:

1 Prepare reports on pollution control and industrial waste

2 Develop plans for environmental improvement of industrial processes

3 A record of hazardous waste

4 The existence of standards for the prevention of major industrial accidents

5 Prepare reports on environmental auditing and programs for environmentally educating and training workers

6 Awareness of local and international environmental requirements and standards for the protection of the environment

\section{Corresponding author}

Rasha Kamal El-Deen El-Mallah can be contacted at: dr.rasha_elmallah@hotmail.com

For instructions on how to order reprints of this article, please visit our website: 